\title{
Assessment of Turbulence Models on Bridge-Pier Scour Using Flow-3D
}

\author{
Chandara Man, Genguang Zhang*, Vouchleang Hong, Shuang Zhou, Yulin Feng \\ College of Water Resources and Architectural Engineering, Northwest A\&F University, Yangling, China \\ Email: *zhanggenguang@nwsuaf.edu.cn, chandaraman168@gmail.com, vouchleanghong888@gmail.com, \\ zhoushuang@nwafu.edu.cn, fengyulin282@nwafu.edu.cn
}

How to cite this paper: Man, C., Zhang, G.G., Hong, V., Zhou, S. and Feng, Y.L. (2019) Assessment of Turbulence Models on Bridge-Pier Scour Using Flow-3D. World Journal of Engineering and Technology, 7, 241-255.

https://doi.org/10.4236/wjet.2019.72016

Received: February 11, 2019

Accepted: March 1, 2019

Published: March 4, 2019

Copyright $\odot 2019$ by author(s) and Scientific Research Publishing Inc. This work is licensed under the Creative Commons Attribution International License (CC BY 4.0).

http://creativecommons.org/licenses/by/4.0/

\section{(c) (i) Open Access}

\begin{abstract}
The main purpose of this paper is to analyze the influence of different turbulence flow models on scouring pit of bridge-pier. Flow-3D software is applied in line with the purpose. The key motivation for this study is to contribute to the Flow-3D software by means of some modification and adjustment in the sediment scour model and shallow water model. An assessment of turbulence model adopted with the parameters of the Melville experiment to estimate the maximum scour-depth was performed. In the simulation results, the alternate eddy formation and shedding were repeated while the Karman vortex street formed behind the pier for the large eddy simulation LES turbulence model is more realistic in the flow phenomenon. The results of the scour development of large eddy simulation (LES) turbulence model were found to be more satisfied than the Renormalized group (RNG) turbulence model and close to the prior experiment results. The simulated scour results were significantly different with the observed data collected from previous literature in the reason of some unsuitability of meshing method in Flow-3D software.
\end{abstract}

\section{Keywords}

Flow-3D, Bridge-Piers Scour, Computational Fluid Dynamics (CFD), Turbulence Model Large Eddy Simulation Model (LES),

Renormalized Group Model (RNG)

\section{Introduction}

Pier, an important part of multi-span bridge, is very important for the safe operation of bridges. In the river, due to the high-velocity flow, the riverbed near the bridge abutment will be seriously scoured, and it also reduces the buried depth of the foundation of bridge piers, leading to the collapse of the bridge and even

${ }^{\star}$ Corresponding author. 
the loss of life and property. It is generally caused by the interference of structures with river flows and characterized by the formation of a scour hole around the piers of bridges. Even though a great deal of time, money, and efforts have been invested to predict bridge scour for an early disaster warning, it is still difficult to accurately analyze the scour development at piers, especially in the three-dimensional space. Therefore, it is necessary to make an accurate prediction of local scour of bridge piers. A series of investigates have been carried out for the development of local scour of bridge piers [1] [2] [3] [4]. Rechardson (2014) have addressed the problem of bridge failures and nearly $60 \%$ of bridges collapses are caused by the scouring and the deficiencies of hydraulic [5]. The collapse of a pier is caused by erosion of a gravel layer of the river channel and local scour at bridge pier that conducts a large scour of the river bed [6]. The Shuang-Yuan Bridge, in Taiwan, constructed in early 1970 but failed during a flood event in 2009 [7]. Therefore, the study about the mechanical process of the bridge-scoured under flood condition and the development of an accurate safety evaluation method was proposed [7] [8].

Mostly, characterize of scouring around the piers can be observed in three different types such as the local, general and contraction scour [9]. For a better prediction of local scour, three-dimensional hydrodynamic models and integrated sediment transport algorithms were developed [10]. Scour mechanism, scour depth and flow structure were performed on many field observations and experimental investigations [11]. Moreover, the designers take seriously on the problem of scouring around the bridge for safe and economical design [12]. Consequently, in the hydraulic engineering sector, numerical modeling is one of the most important features to realize about flow field characteristic and sediment scour development before construction of the hydraulic structure (e.g. bridge, spillway, and dam construction). For example, several studies proposed ANSYS Fluent model to predict the local scour around bridge-pier [8] [13] [14] [15], which gives an acceptable agreement in the scour simulation with the experiment. Otherwise, SSIIM software used to exam the scour near the abutment in the different shape [16], which exposes an important software to simulate the bridge-pier scour. Boujia (2017) has proposed a numerical model, namely, Code-Aster software to investigate the problem of bridge failure [17]. In addition, Flow-3D was used to simulate the local scour, which is one of the useful software for hydraulic engineering design and give a significant association between the simulation and experiment [18] [19] [20] [21]. A more comprehensive description can be found in an investigation of the flow field in the local scour by using the RNG $(k-\varepsilon)$, which leads the flow velocity to overestimate near the bed [22]. However, several studies showed a significant result in the flow field investigation by proposing the RNG $(k-\varepsilon)$ turbulence model [23] [24]. Moreover, with the numerical modeling, large eddy simulation (LES) turbulence model was proposed to investigate the local scour in various structures [24] [25]. An investigation of flow field and bed-load deformation around the cylindrical has been proposed by [26]. The present study, however, is significant for the ap- 
plicable of the turbulence flow models; and the modification and adjustment in the sediment scour model; and the Shallow water flow model in reason to make an accuracy prediction the scour development around bridge-pier in the Flow-3D software. Although there are more software packages proposed to estimation the sediment scour around the bridge-pier, it is still a limited study by using Flow-3D software.

The objective of this research is to perform an assessment of turbulence model with the available bed-load transport rate equation on bridge-pier scour by using Flow-3D. In addition, the reference materials of the Melville experiment were used to design in the model. The Reynolds Average Navier-Stokes equation, which is the basic governing equation, is used in the model based on the transient to predict the interval stress related with the exception of turbulence parameterization [27]. In addition, this works used two options of turbulence model in the simulation, namely, Renormalized group and large eddy simulation turbulence model. In the process of assessment, the verification of the flow field, scour depth and scour shape were proposed in this study.

\section{Numerical Model}

\subsection{Flow Field Simulation}

The Reynolds-Averaged Navier Stokes (RANS) equations solved in the hydrodynamic model. The Volume of Fluid (VOF) is a typical model to track the water surface for solving the nonlinear Navier-Stokes equation in 3D flow, and especially for applying on the liquid motion [28]. Furthermore, it was used to investigate the vortex in a box test to calculate the volume tracking algorithm [29]. Xiaofeng (2008) presents a new approach of VOF scheme to diminish the computational time [15]. In addition, the FAVOR method is used to figure out the zone of flow obstacles and demonstrate the boundaries of the domain [15].

\subsubsection{Reynolds Average Navier-Stokes (RANS)}

The RANS equations are given as

$$
\begin{aligned}
\frac{\partial}{\partial x_{i}}\left(u_{i} A_{i}\right) & =0 \\
\frac{\partial u_{i}}{\partial t}+\frac{1}{V_{F}}\left(u_{j} A_{j} \frac{\partial u_{i}}{\partial x_{j}}\right) & =-\frac{1}{\rho} \frac{\partial p}{\partial x_{i}}+G_{i}+f_{i}
\end{aligned}
$$

where $x=$ represents the coordinate, $u_{i}=$ mean velocity, $A_{i}=$ fractional area open to flow, $t=$ time, $V_{F}=$ fractional volume open to flow, $p=$ pressure, $\rho$ = fluid density, $G_{i}=$ the body accelerations, and $f_{i}=$ the viscous accelerations.

\subsubsection{Turbulence Model}

In Flow-3D modeling, the turbulent flow model has five schemes: Large Eddy Simulation (LES), Renormalization-Group (RNG), the two-equation $(k-\varepsilon)$, one equation turbulent energy $(k)$, and Prandtl's mixing length theory [30]. The RNG and LES turbulence model were used to perform the CFD via Flow-3D 
model.

1) Renormalized group (RNG) model

The RNG is reformed to develop a two-equation $k-\varepsilon$ model in many years later [31]. The $k-\varepsilon$ model, which is the important key to predict the effects of turbulence, is the foundation principle to observe Reynold's stress comparably as the viscous stress. Based on the Boussinesq approximation, the turbulence eddy viscosity $\left(v_{t}\right)$ is the key to solve the turbulence equation.

$$
v_{t}=C_{\mu} \frac{k^{2}}{\varepsilon}
$$

where $C_{\mu}=$ an empirical coefficient; $k$ and $\varepsilon=$ turbulence kinetic energy and dissipation, respectively.

In the standard $k-\varepsilon$ turbulence model, both $k$ and $\varepsilon$ are determined by Equations (4) and (5)

$$
\begin{gathered}
\frac{\partial k}{\partial t}+u_{i} \frac{\partial k}{\partial x_{i}}=\frac{\partial}{\partial x_{i}}\left(\frac{v_{t}}{\sigma_{k}} \frac{\partial k}{\partial x_{i}}\right)+v_{t}\left(\frac{\partial u_{i}}{\partial x_{j}}+\frac{\partial u_{j}}{\partial x_{i}}\right) \frac{\partial u_{i}}{\partial x_{j}}-\varepsilon \\
\frac{\partial \varepsilon}{\partial t}+u_{i} \frac{\partial k}{\partial x_{i}}=\frac{\partial}{\partial x_{i}}\left(\frac{v_{t}}{\sigma_{\varepsilon}} \frac{\partial \varepsilon}{\partial x_{i}}\right)+C_{1} \frac{\varepsilon}{k} v_{t}\left(\frac{\partial u_{i}}{\partial x_{j}}+\frac{\partial u_{j}}{\partial x_{i}}\right) \frac{\partial u_{i}}{\partial x_{j}}-C_{2} \frac{\varepsilon^{2}}{k}
\end{gathered}
$$

where $C_{1}=1.44, C_{2}=1.92$ (both of them are constants for adjusting the generation and dissipation of turbulence in $\varepsilon$ equation), $\sigma_{k}=1.0$, and $\sigma_{\varepsilon}=1.3$.

2) Large eddy simulation model

Large eddy simulation model is one option of the turbulence model in computation fluid dynamic. This equipment has the ability to decrease the computational cost by neglecting the smallest length scales, which the most computations are expensive to resolve. Furthermore, significant practical problems are generated in the storage and analysis of large data. LES kinematic eddy viscosity $\left(v_{T}\right)$ perform as [30]

$$
v_{T}=(c L)^{2} \sqrt{2 e_{i j} 2 e_{i j}}
$$

where $c=$ constant $(0.1-0.2), L=$ the length scale and $e_{i j}=$ the strain rate tensor components.

\subsection{Sediment Scour Model}

The development empirical model must be used to simulate the flow dynamics of the specified sediment grain. In Flow-3D modeling, two states need to consider are suspended and packed sediment which packed sediment replace in the form of bed load transport [30] [32]. The Solusby-Whitehouse equation is used to calculate the critical Shields parameter.

The dimensionless parameter $T$ is computed by

$$
T=d\left[\frac{\rho\left(\rho_{s}-\rho\right) g}{\mu^{2}}\right]^{1 / 3}
$$

where $\mu=$ the dynamic viscosity of fluid, $\rho_{s}=$ the fluid density, $d=$ the 
particle diameter, and $g=$ the acceleration of gravity.

Equation (8) is applied to calculate the critical shear stress of sediment in case of flat riverbed [33].

$$
\tau_{b, c r}=\rho g(s-1) d_{50} \theta_{c r}
$$

where $\tau_{b, c r}=$ critical shear stress of sediment; $s=$ specific density $\left(\rho_{s} / \rho\right)$; $d_{50}=$ medium diameter of sediment particle; and $\theta_{c r}=$ critical Shields number.

The Soulsby-Whitehouse equation is used to calculate the dimensionless critical Shields parameter in form of formulas:

$$
\theta_{c r}=\frac{0.3}{1+1.2 T}+0.055[1-\exp (-0.02 T)]
$$

In the natural, the bed of the river is not flat. For sloping surfaces case, the critical Shields parameter is modified related to the angle of repose [34]:

$$
\theta_{c r}^{\prime}=\theta_{c r} \frac{\cos \psi \sin \beta+\sqrt{\cos ^{2} \beta \tan ^{2} \varphi-\sin ^{2} \psi \sin ^{2} \beta}}{\tan \varphi}
$$

where $\beta=$ the angle of slope of bed, $\varphi=$ the angle of repose for sediment (default is $32^{\circ}$ ), and $\psi=$ the angle between the flow and the upslope direction.

The local bed shear stress is computed through the below formula:

$$
\tau=\operatorname{\theta gd}\left(\rho_{\mathrm{s}}-\rho\right)
$$

where $\theta=$ the Shield parameter, $d=$ the particle diameter.

Sediment transport rate is one of the key criteria to estimate the scour and it shows as the volume of sedimentary material. Bed load transport is the processing of rolling over the surface of the sediment packed bed. A correct prediction of sediment rate is a key factor in the improvement of scour depth prediction. In some cases, modification of sediment transport equations leads to a more accurate prediction of scouring phenomenon [35] [36]. In the Flow-3D, the dimensionless bed load transport rate of sediment can be applied through the Equation (12).

- Meyer-Peter and Müller [37]

$$
\Phi=\left(\theta-\theta_{c r}^{\prime}\right)^{1.5}
$$

The volumetric bed-load transport rate $\left(q_{b}\right)$ is applied through the below equation:

$$
q_{b}=\Phi\left[g\left(\frac{\rho_{s}-\rho}{\rho}\right) d^{3}\right]^{\frac{1}{2}}
$$

In addition, the drag force coefficient for bottom shear stress is used in the Shallow water flow, which is one of physics in Flow-3D [30]. The Shallow water flow is applied in case turbulent associate with the one-fluid. Equation (14) was used to estimate the drag force coefficient related with the flow depth and the 
surface roughness.

$$
C_{d}=\left[\frac{\kappa}{B+\ln \left(\frac{k_{s}}{30 y_{0}}\right)}\right]^{2}
$$

where $\kappa=$ the Von Karman constant, 0.40, $B=0.71, y_{0}=$ the fluid depth, and [38] assumed $k_{s}=2 d_{50}$ the surface roughness.

\subsection{Experiment Setup}

The result of Melville (1975) experiment was used to verify the accuracy of the 3D simulation method by using CFD. The results of the Melville experiment [39] was used to compare with numerical results that experiment was installed with a medium diameter of sand $\left(d_{50}=0.385 \mathrm{~mm}\right)$, density $2650 \mathrm{~kg} / \mathrm{m}^{3}$, flume with a section $19 \mathrm{~m}$ long and $0.456 \mathrm{~m}$ wide, flow depth $(H=15 \mathrm{~cm})$, a diameter of pile $(d=5.08 \mathrm{~cm})$ and slope of flume $1 / 10,000$. In addition, the average velocity was used as $0.25 \mathrm{~m} / \mathrm{s}$ at the inlet.

The proposed simulation method was used to simulate the scouring behavior adopted with the procedure and materials of Melville experimental. The flow field around the pile has no effect if the distance from the inlet to the pile center is $12 d$ [40]. Therefore, the geometry was set as $45 d(2.286 \mathrm{~cm}) ; 30 d(1.524 \mathrm{~cm})$ for the whole length and distance from the pile center to upstream, respectively. In the simulation, the grid spacing plays as a key point [21]. Therefore, a more-refine element was meshed around the pile and riverbed for making a better observation of the scour development. In the simulation, the mesh size was set $0.5 \mathrm{~cm}$ for the refined places and $1 \mathrm{~cm}$ elsewhere [14]. Two mesh planes ( $\mathrm{x}$ and y directions) were set around the pier to increase the model accuracy and two blocks were built at the inlet and outlet of the channel to prevent upward movement of sediments at the upstream. Figure 1(b) shows the boundary condition in scour model establishment which set the specified velocity at the inlet, outlet and the top with specified pressure, and the right and left sides, and the bottom with the wall.

\section{Results and Discussion}

\subsection{Flow Field Verification}

After 5 minutes of running the calculation, the simulation of depth average velocity around the cylindrical is illustrated in Figure 2. Through the simulation, it can be observed that the red colors in both beside of cylindrical of both cases (RNG and LES turbulence model) have the highest velocity, while the blue color at the downstream behind the pier has the lowest velocity. The simulation results are consistent with [41] which reported at the downstream of the pier, the longitudinal velocity is negative viewing the flow towards the surface of the water. The streamwise velocity changes to positive and thus increases but decreases in- 
ward the scour hole. Wake vortex is the main point to consider before bridge construction [39]. There is no vortex shedding behind the pier in Figure 2(a), whereas Figure 2(b) is formed Karman vortex street behind the pier. In addition, Figure 2(b) shows the curl at the downstream in the simulation flow field, where it can be investigated the stronger vortex is, and the greater curl exists. Therefore, the flow phenomenon behind the pier is more realistic in the LES turbulence model and suitable than the RNG turbulence model in calculating the water flow. Other studies also confirm that the LES turbulence model may resemble the shape and behavior of vortices better in comparison with other common turbulence models [42] [43]. To understand the magnitude of velocity gradient, the initial velocity is $0.25 \mathrm{~m} / \mathrm{s}$ but the velocity is slightly increased to over $0.30 \mathrm{~m} / \mathrm{s}$ in the condition of the simulation time at the sides of the pier where the red colors can be noted in Figure 2. Significantly, the depth-averaged velocity is almost stable around $0.25 \mathrm{~m} / \mathrm{s}$ at the front of the pier, but it is slightly decreased at the downstream behind the pier where it can be noted the blue color in Figure 2.

In the other way, Figure 3(a) and Figure 3(b) shows the sectional view of the behavior of the flow velocity vector at the water level $4 \mathrm{~mm}$ up around cylinder, and Figure 3(c) illustrates the behavior of the flow velocity in the Melville experimental [39]. The backflow occurs in the wake of piers, which can be noted the effecting of the flow pattern trendy near the wake were strong at the upflow and weak at the backflow. Through the simulation, it can be noted that the vortex moving around the pier in both simulation and experimental results are acceptable.

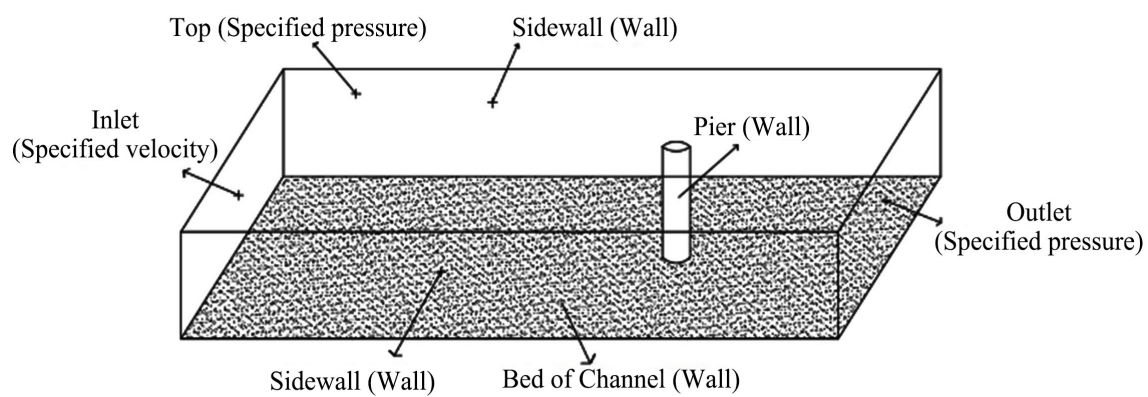

(a)

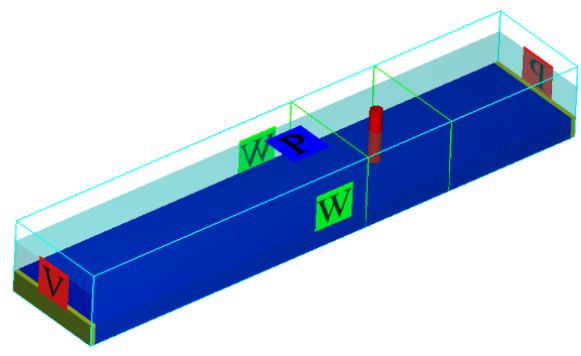

(b)

Figure 1. (a) Boundary conditions in the numerical model; (b) Geometry structure in the model around a cylindrical pier. 


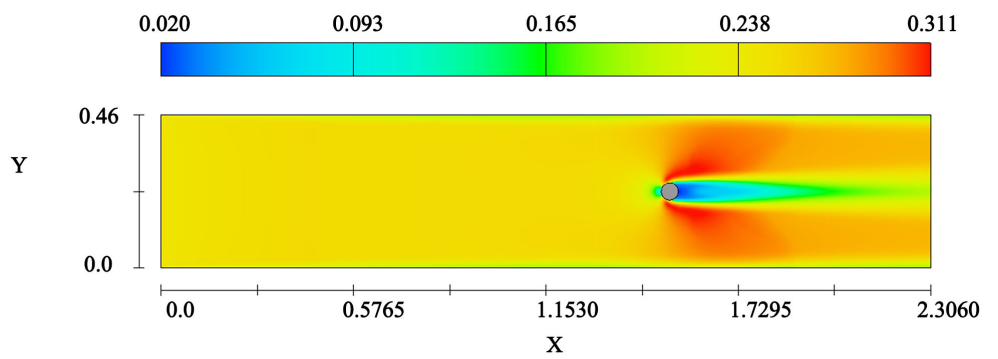

(a)

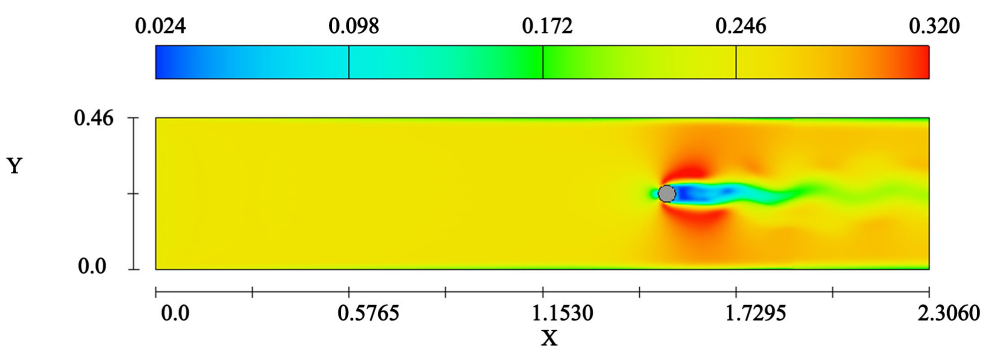

(b)

Figure 2. Depth-averaged velocity simulation after 5 minutes using (a) RNG turbulence model and (b) LES turbulence model.

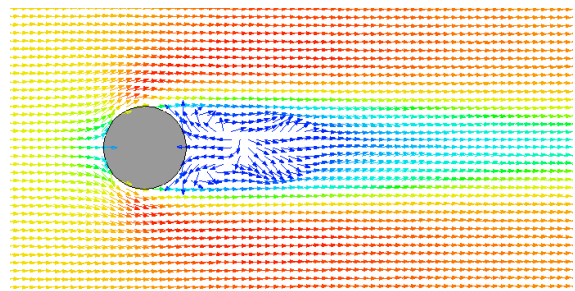

(a)

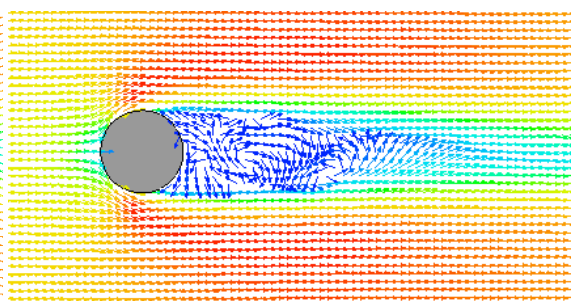

(b)

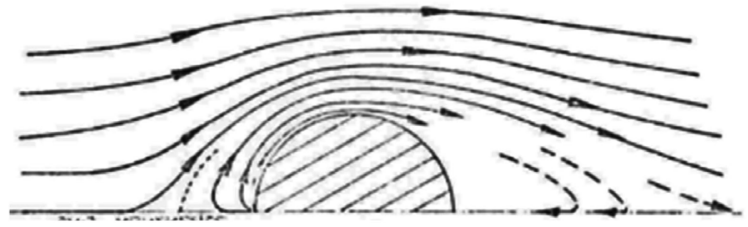

(c)

Figure 3. The flow directions across the cylinder (a) RNG simulation results (b) LES simulation results and (c) Experimental measurement (Melville 1975).

\subsection{Verification of Scour Depth Prediction}

Figure 4 shows the flow velocity distribution diagrams on both sides of the vertical flow direction of the RNG and LES turbulence model, respectively. It can be observed that at the initial time $(t=0 \mathrm{~s})$, due to the existing of the pier, the increased the flow velocity on both sides of the pier could be due to turbulence features around the pier, especially the increase of the bottom flow velocity, causing the shear stress of the bed surface. Moreover, in the time of the sand surface exceeds the shear stress, the scouring occurs. The water flows down on behind the pier at the upstream surface to form a vortex. At $t=600 \mathrm{~s}$, the whirlpool, the horseshoe vortex around the pier was developed, and the scouring 
depth increased. The vortex on both sides of the pier further developed and the scouring further intensified at $t=1200 \mathrm{~s}$, but it will gradually be stabilized at $\mathrm{t}=$ $1800 \mathrm{~s}$. Through the above analysis, the scouring around the pier is related to the rolling of the water flow on both sides. The development of the scouring promotes the further development of the scouring pit and the whole process. Based on the simulation running, it can be noted that the scouring of both RNG and LES turbulence model in the early stage is fast but the scour depth development in LES turbulence model is deeper than RNG turbulence model.

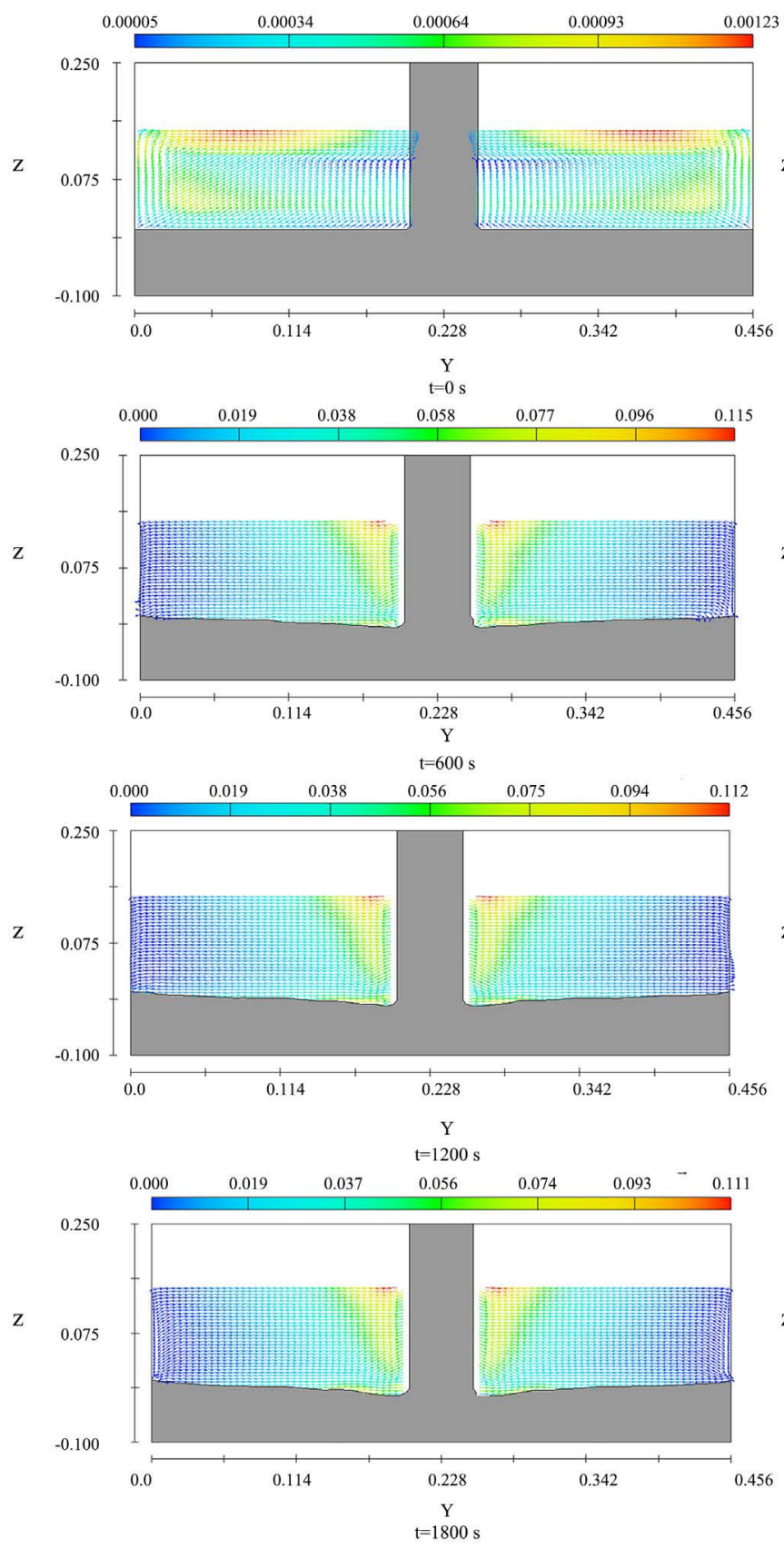

(a)
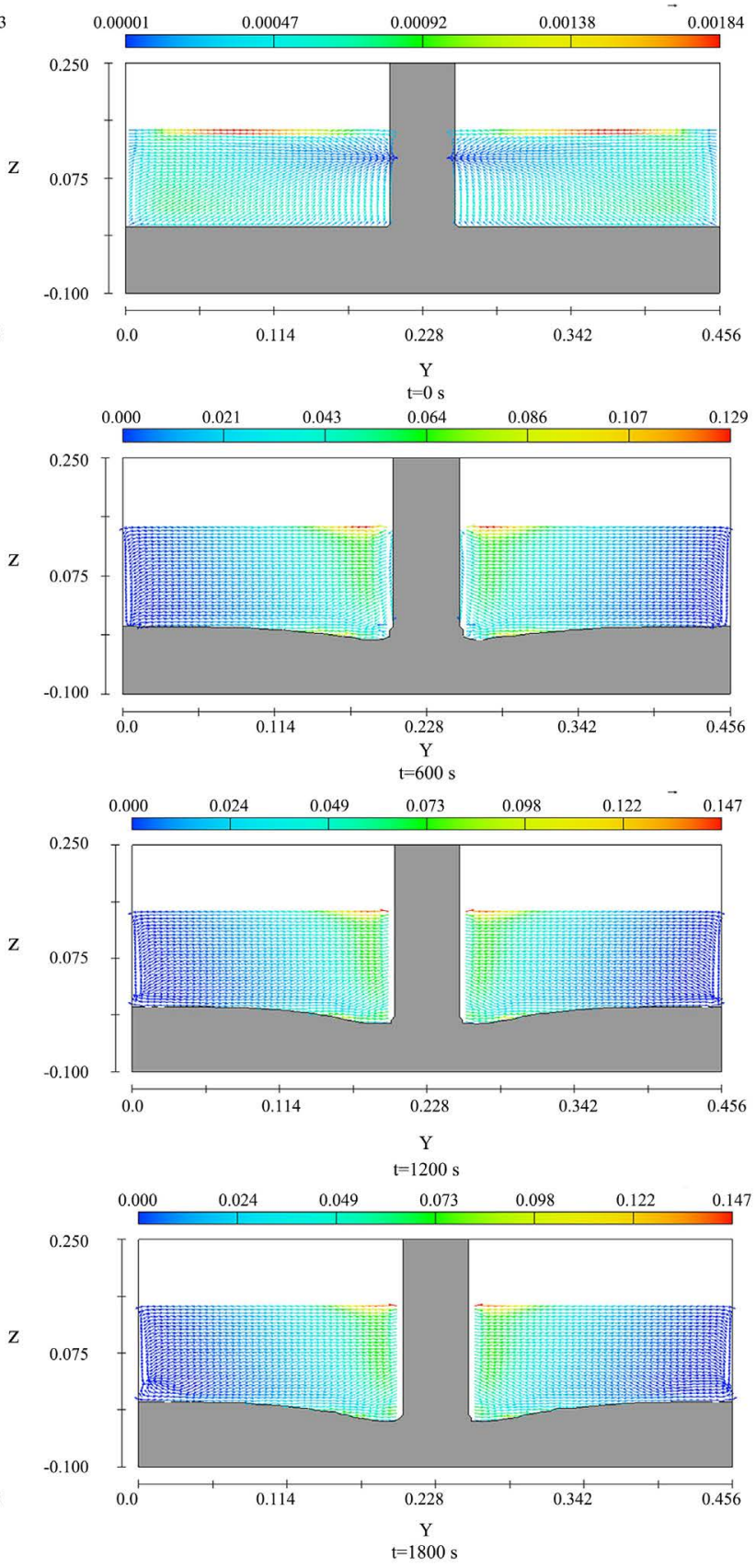

(b)

Figure 4. Flow velocity distribution at different times in the cross section. (a) RNG simulation results; (b) LES simulation results. 
In the equilibrium scour model, the scour depth development is plotted in Figure 5. It shows the scour developed rapidly in the first 7 minutes, which the shear stress extremely exceeds the corresponding critical shear stress and it led to scouring the space around the pier. The scour depth developed strongly at the start point of time but it developed slowly in the late period.

By using the same experimental conditions provided by the Melville, the maximum scour depths are $3.06 \mathrm{~cm}$ and $3.46 \mathrm{~cm}$ simulated by using RNG and LES turbulence model, respectively, by proposing the Flow-3D model, but it was $4.00 \mathrm{~cm}$ in the experiment [39]. In the discussion above, the flow field in the simulation is almost the same as in experiment result but the value of scour depth results are quite different. Therefore, two main points found in the model that make it different are: 1) There is a limitation of applied mesh method in Flow-3D [18] [19] that the software uses the FAVOR method to define the regions of geometric in the rectangular grid, which the combination of gridding of rectangular grids are the flexibility to deform the objects and 2) In this study, it directly applied the sediment transport model in the simulation of the Flow-3D model. In addition, applied the different sediment transport equation is one of the main factors caused a different scour-depth [44].

\subsection{Scour Shape Verification}

Figure 6(a) and Figure 6(b) show the contours of the simulation using the LES and RNG turbulence model at the local scour shapes after $30 \mathrm{~min}$. It can be observed that the finer materials in the face and on both sides of the pier are strongly removed compared with another sediment deposition is less and reveal a significant result with experimental results [14] [39]. Due to the fact that the velocities in both sides are the highest value and rapidly carries the sediment particles, once it encompasses the pier. Figure 6(b) shows the discrepancy as the experimental data and numerical model of [39] found a big discrepancy showing imperfection of the $k-\varepsilon$ turbulence model for 3D flow. The topographic contour of the local scour shape in both cases of the LES and RNG turbulence model show a slight dissimilar trend, whereas the reflection of flow velocity proposed RNG turbulence model spread the contour level of sediment net change from the edge of cylindrical wider than LES turbulence model as seen in Figure 6(a) and Figure 6(b). To investigate the vortex strength in Figure 2, the development of scour depth by using LES turbulence model is better than the RNG turbulence model. This is in agreement with previous results [45], which the scour shape of the experimental data and LES turbulence model ushers in a significant phenomenon. Although the large eddy simulation can accurately simulate the sediment scour in front of the pier, there are still high computing resources and large calculations. In addition, the downstream mound of the fine sand in both cases of the simulation shows a good similarity with the Melville experiment result as seen in Figure 6(c) [39]. 


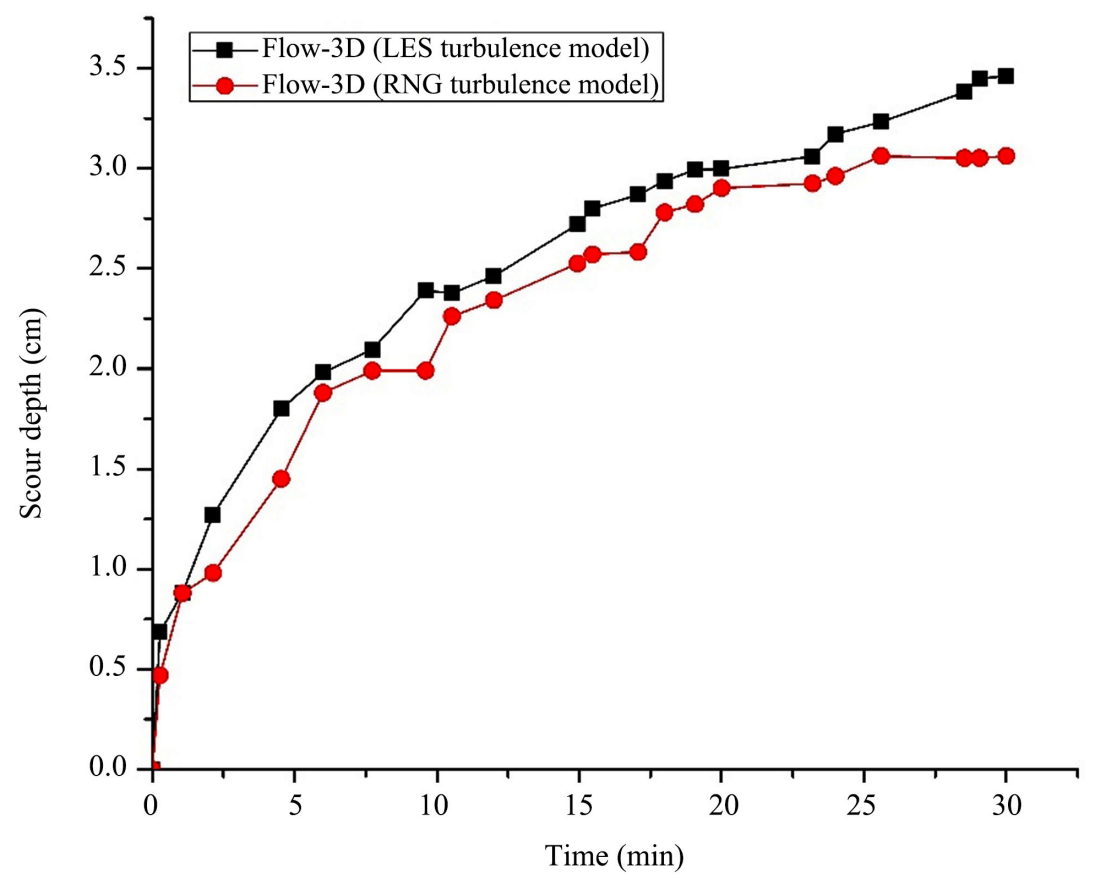

Figure 5. Scour depths over simulation time (Flow rate $17.12 \mathrm{~L} / \mathrm{sec}$ ).

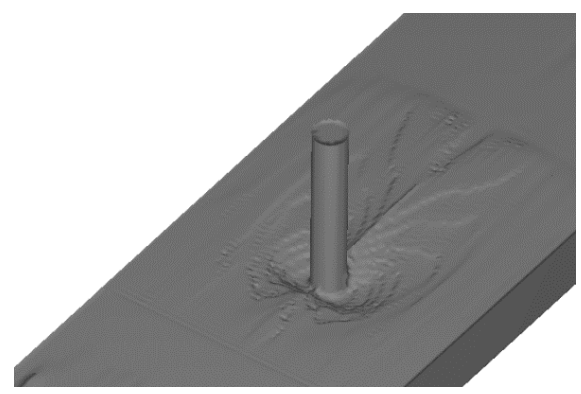

(a)

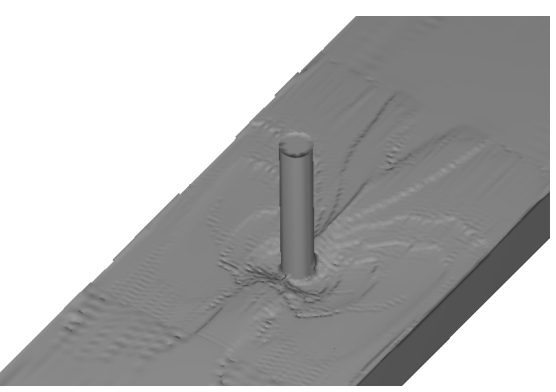

(b)

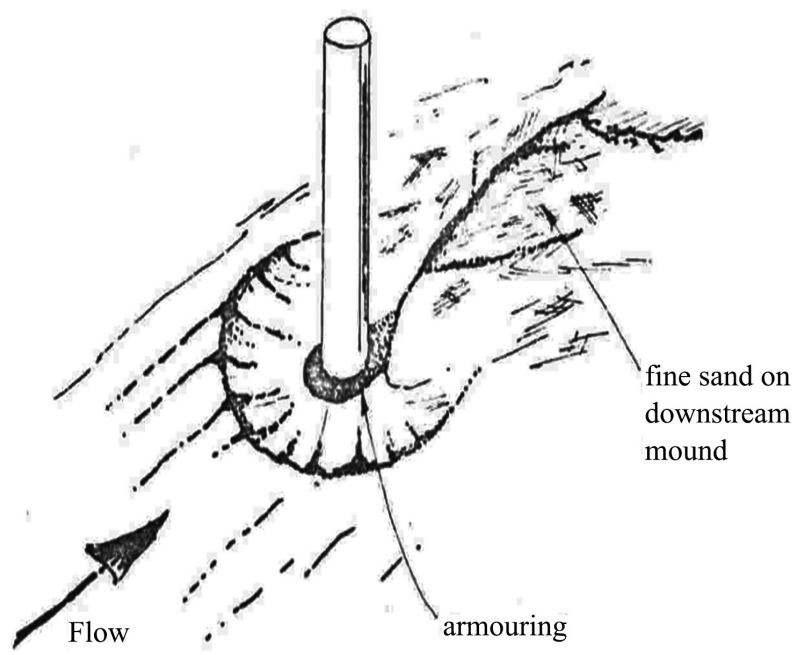

(c)

Figure 6. The scour hole shape around bridge-pier of simulation results and experiment. (a) Large eddy simulation (LES) simulation; (b) Renormalized group (RNG) simulation; (c) Experiment results (Melville 1975). 


\section{Summary and Conclusions}

Flow-3D, one of the CFD models, is applied in this study. In addition, two options of turbulence model (RNG and LES turbulence model) with the Meyer-Peter sediment transport model are used to simulate the bridge scour adopted with the parameters of Melville. The verification of flow field is acceptable with the Melville experimental result, whereas the alternate eddy formation and shedding are repeated and the Karman vortex street is formed behind the pier in the simulation of LES turbulence model. Therefore, the flow phenomenon behind the pier is more realistic. The limitation of the applied mesh method in Flow-3D software has influenced the results, which are found to be under the prediction. Nevertheless, the development of the scour depth with LES turbulence model is obviously more significant than RNG turbulence model and close to the experiment value. Although the large eddy simulation can accurately simulate the sediment scour in front of the pier, its application will be more extensive with the development of computer technology.

Further studies may focus on two main points to improve the sediment scour simulation in Flow-3D modeling to develop the mesh method and to apply the sediment transport model by using the own code-writing.

\section{Acknowledgements}

This research was supported by the National Natural Science Foundation of China, No. 5187922. The authors express their gratitude to Mr. Saleh Shahriar, College of Economics and Management, Northwest A\&F University, Shaanxi, Yangling, China and Miss. Liu Jiaqi, College of Water Resources and Architectural Engineering, Northwest A\&F University, China, for their assistance in the linguistic improvement of the manuscript.

\section{Conflicts of Interest}

The authors declare no conflicts of interest regarding the publication of this paper.

\section{References}

[1] Melville, B.W. and Raudkivi, A.J. (1977) Flow Characteristics in Local Scour at Bridge Piers. Journal of Hydraulic Research, 15, 373-380. https://doi.org/10.1080/00221687709499641

[2] Raudkivi, A.J. (1977) Effect of Sediment Gradation on Clear Water Scour. Journal of the Hydraulics Division, 103, 1209-1213.

[3] Raudkivi, A.J. and Ettema, R. (1987) Closure of "Scour at Cylindrical Bridge Piers in Armored Beds". Journal of Hydraulic Engineering, 11, 713-731.

[4] Breusers, H.N.C., Nicollet, G. and Shen, H.W. (1977) Local Scour around Cylindrical Piers. Journal of Hydraulic Research, 15, 211-252.

[5] Richardson, E.V. (2014) Historical Development of Bridge Scour Evaluations. North American Water and Environment Congress \& Destructive Water, Anaheim, 22-28 June 1996. 
[6] Raudkivi, A.J. and Ettema, R. (1985) Scour at Cylindrical Bridge Piers in Armored Beds. Journal of Hydraulic Engineering, 111, 713-731.

[7] Hung, C.-C. and Yau, W.-G. (2017) Vulnerability Evaluation of Scoured Bridges under Floods. Engineering Structures, 132, 288-299.

https://doi.org/10.1016/j.engstruct.2016.11.044

[8] Xiong, W., Kong, B. and Cai, C.S. (2016) Reliable Bridge Scour Simulation Using Eulerian Two-Phase Flow Theory. Journal of Computing in Civil Engineering, 30, 1-11. https://doi.org/10.1061/(ASCE)CP.1943-5487.0000570

[9] Hamidi, A. and Siadatmousavim S.M. (2017) Numerical Simulation of Scour and Flow Field for Different Arrangements of Two Piers Using SSIIM Model. Ain Shams Engineering Journal, 9, 2415-2426.

[10] Richardson, J.E. and Panchang, V.G. (1998) Three-Dimensional Simulation of Scour-Inducing Flow at Bridge Piers. Journal of Hydraulic Engineering, 124, 530-540. https://doi.org/10.1061/(ASCE)0733-9429(1998)124:5(530)

[11] Li, G. (2013) 3D Numerical Simulation of Flow and Local Scour around a Spur Dike. IAHR World Congress, Chengdu, 8-13 September 2013, 1-9.

[12] Mubeen Beg, S.B. (2013) Scour Reduction around Bridge Piers: A Review. International Journal of Engineering Inventions, 2, 7-15.

[13] Ali, K.H.M. and Karim, O. (2002) Simulation of Flow around Piers. Journal of Hydraulic Research, 40, 161-174. https://doi.org/10.1080/00221680209499859

[14] Xiong, W., Kong, B. and Kong, X. (2016) Simulations and Analyses for Bridge-Scour Development Using a Dynamic-Mesh Updating Technique. Journal of Computing in Civil Engineering, 30, 1-11. https://doi.org/10.1061/(ASCE)CP.1943-5487.0000458

[15] Liu, X.F. and García, M.H. (2008) Three-Dimensional Numerical Model with Free Water Surface and Mesh Deformation for Local Sediment Scour. Journal of Waterway, Port, Coastal, and Ocean Engineering, 13, 203-217. https://doi.org/10.1061/(ASCE)0733-950X(2008)134:4(203)

[16] Mohamed, Y.A., Abdel-Aal, G.M. and Nasr-Allah, T.H. (2016) Experimental and Theoretical Investigations of Scour at Bridge Abutment. Journal of King Saud University-Engineering Sciences, 28, 32-40.

https://doi.org/10.1016/j.jksues.2013.09.005

[17] Boujia, N., Schmidt, F., Siegert, D., Van Bang, D.P. and Chevalier, C. (2017) Modelling of a Bridge Pier Subjected to Scour. In: Lefebvre, F. and Souquet, P., Eds., Procedia Engineering, Vol. 199, Elsevier, Amsterdam, 2925-2930. https://doi.org/10.1016/j.proeng.2017.09.343

[18] Vasquez, J.A. and Walsh, B.W. (2009) CFD Simulation of Local Scour in Complex Piers under Tidal Flow. 33rd IAHR Congress: Water Engineering for a Sustainable Environment, 913-920.

[19] Bayón-Barrachina, A., Valero, D., Vallès-Morán, F. and López-Jiménez, P.A. (2014) Comparison of CFD Models for Multiphase Flow Evolution in Bridge Scour Processes. 5th International Junior Researcher and Engineer Workshop on Hydraulic Structures, Spain.

[20] Basser, H., Ardeshir, A. and Karami, H. (2012) Numerical Simulation of Flow Pattern around Spur Dikes Series in Rigid Bed. 9 th International Congress on Civil Engineering, Isfahan, Iran, 8-10 May 2012, 1-6.

[21] Kocaman, S. (2014) Prediction of Backwater Profiles Due to Bridges in a Compound Channel Using CFD. Advances in Mechanical Engineering, 6. 
https://doi.org/10.1155/2014/905217

[22] Ahmed, F. and Rajaratnam, N. (1998) Flow around Bridge Piers. Journal of Hydraulic Engineering, 124, 288-300. https://doi.org/10.1061/(ASCE)0733-9429(1998)124:3(288)

[23] Bradbrook, K.F., Lane, S.N., Richards, K.S., Biron, P.M. and Roy, A.G. (2001) Role of Bed Discordance at Asymmetrical River Confluences. Journal of Hydraulic Engineering, 127, 351-368. https://doi.org/10.1061/(ASCE)0733-9429(2001)127:5(351)

[24] Haltigin, T.W., Biron, P.M. and Lapointe, M.F. (2007) Predicting Equilibrium Scour-Hole Geometry near Angled Stream Deflectors Using a Three-Dimensional Numerical Flow Model. Journal of Hydraulic Engineering, 133, 983-988. https://doi.org/10.1061/(ASCE)0733-9429(2007)133:8(983)

[25] Koken, M. and Constantinescu, G. (2008) An Investigation of the Flow and Scour Mechanisms around Isolated Spur Dikes in a Shallow Open Channel: 2. Conditions Corresponding to the Final Stages of the Erosion and Deposition Process. Water Resources Research, 66, 297-301. https://doi.org/10.1029/2007WR006489

[26] Roulund, A., Sumer, B.M., Fredsøe, J. and Michelsen, J. (2005) Numerical and Experimental Investigation of Flow and Scour around a Circular Pile. Journal of Fluid Mechanics, 534, 351-401. https://doi.org/10.1017/S0022112005004507

[27] Falconer, R.A. (1991) Computational Fluid Dynamics. By M. B. A BBOTT and D. R. BASCO. Longman, 425 pp. $£ 32$. Journal of Fluid Mechanics, 229, 689. https://doi.org/10.1017/S0022112091213233

[28] Hirt, C.W. and Nichols, B.D. (1981) Volume of Fluid (VOF) Method for the Dynamics of Free Boundaries. Journal of Computational Physics, 39, 201-225. https://doi.org/10.1016/0021-9991(81)90145-5

[29] Rider, W.J. and Kothe, D.B. (1998) Reconstructing Volume Tracking. Journal of Computational Physics, 141, 112-152.

[30] (2009) Flow-3D User's Manuals. Flow Science, Inc.

[31] Yakhot, V. and Smith, L.M. (1992) The Renormalization Group, the $\varepsilon$-Expansion and Derivation of Turbulence Models. Journal of Scientific Computing, 7, 35-61. https://doi.org/10.1007/BF01060210

[32] Dey, S. (2014) Fluvial Hydrodynamics.

[33] Kanellopoulos, P.M. (1998) Incipient Motion under Shallow Flow Conditions. Thesis, 170.

[34] Soulsby, R. (1997) Dynamics of Marine Sands: A Manual for Practical Applications. Thomas Telford, London.

[35] Dodaro, G., Tafarojnoruz, A., Calomino, F., Gaudio, R., Stefanucci, F., Adduce, C. and Sciortino, G. (2014) An Experimental and Numerical Study on the Spatial and Temporal Evolution of a Scour Hole Downstream of a Rigid Bed. River Flow, 1415-1422.

[36] Dodaro, G., Tafarojnoruz, A., Sciortino, G., Adduce, C., Calomino, F. and Gaudio, R. (2016) Modified Einstein Sediment Transport Method to Simulate the Local Scour Evolution Downstream of a Rigid Bed. Journal of Hydraulic Engineering, 142, Article ID: 04016041. https://doi.org/10.1061/(ASCE)HY.1943-7900.0001179

[37] Dey, S. (2014) Bed-Load Transport. In: Fluvial Hydrodynamics, Springer-Verlag, Berlin, Heidelberg, 261-326.

[38] Cheng, N.-S. and Chiew, Y.-M. (1998) Pickup Probability for Sediment Entrainment. 
Journal of Hydraulic Engineering, 125, 789-789.

[39] Melville, B.W. (1975) Local Scour at Bridge Sites. University of Auckland, Auckland.

[40] Sarker, Md.A. (1998) Flow Measurement around Scoured Bridge Piers Using Acoustic-Doppler Velocimeter (ADV). Flow Measurement and Instrumentation, 9, 217-227. https://doi.org/10.1016/S0955-5986(98)00028-4

[41] Soltani-Gerdefaramarzi, S., Afzalimehr, H., Chiew, Y.-M., Gallichand, J. and Ghasemi, M. (2013) Turbulent Characteristics in Flow Subjected to Bed Suction and Jet Injection as a Pier-Scour Countermeasure. International Journal of Hydraulic Engineering, 2, 93-100.

[42] Calomino, F., et al. (2018) Experimental and Numerical Study of Free-Surface Flows in a Corrugated Pipe. Water, 10, 638. https://doi.org/10.3390/w10050638

[43] Calomino, F., Tafarojnoruz, A., De Marchis, M., Gaudio, R. and Napoli, E. (2015) Experimental and Numerical Study on the Flow Field and Friction Factor in a Pressurized Corrugated Pipe. Journal of Hydraulic Engineering, 141, Article ID: 04015027. https://doi.org/10.1061/(ASCE)HY.1943-7900.0001046

[44] Gaudio, R., Tafarojnoruz, A. and De Bartolo, S. (2013) Sensitivity Analysis of Bridge Pier Scour Depth Predictive Formulae. Journal of Hydroinformatics, 15, 939-951. https://doi.org/10.2166/hydro.2013.036

[45] Burnham, J. (2011) Modelling Dams with Computational Fluid Dynamics: Past Success and New Directions. Anual Conference of Association of State Dam Safety Officials, 855-893. 